\title{
Leishmaniose visceral canina no município de São Vicente Férrer, Estado de Pernambuco, Brasil
}

\section{Canine visceral leishmaniasis at the urban area of the Municipality of São Vicente Férrer in the State of Pernambuco, Brazil}

\author{
Otamires Alves da Silva, ${ }^{*}$ Geovania Maria da Silva Braga**
}

\begin{abstract}
Resumo
Iniciou-se um estudo sobre a ocorrência de leishmaniose visceral canina em cães do município de São Vicente Férrer no estado de Pernambuco. No período de julho de 2003 a julho de 2005, foram coletadas amostras de sangue de 503 cães domésticos, de diferentes localidades, escolhidos aleatoriamente, para exame pelo teste de imunofluorescência indireta (IFI). Foram processadas preliminarmente 503 amostras de soro, das quais 12,3\% (62 amostras) estavam positivas para Leishmania. Quanto às titulações encontradas nos soros reagentes, 77,4\% (48 amostras) tiveram títulos de 1:40; 9,6\% (6 amostras), 1:80; $8,0 \%$ (5 amostras), 1:160; 3,2\% (2 amostras) e 1:320 e 1,6\% (1 amostra) 1:640. A partir desse resultado foram selecionados 20 dos cães sorologicamente positivos para realização do aspirado de medula óssea. Destes, $85 \%$ (17) apresentaram formas amastigotas de Leishmania sp. Este é o primeiro registro do encontro de cães sorologicamente positivos para Leishmania no município de São Vicente Férrer, estado de Pernambuco, Brasil.
\end{abstract}

Palavras-chave: leishmaniose visceral canina; zoonoses; imunodiagnóstico.

\begin{abstract}
A study was initiated on the occurrence of Visceral Canine leishmaniasis in dogs of the Municipality of São Vicente Férrer in the state of Pernambuco. In the period of July of 2003 the July of 2005, blood samples of 503 domestic dogs were collected from different localities, randou by and they were examined by using immunoflorecens test (IFAT). A total of 503 samples of serum were processed preliminarily of which $12.3 \%$ (62 samples) were positive for visceral leishmaniasis. Where $77.4 \%$ (48 samples) had headings of 1:40; $9.6 \%$ (6 samples) 1:80; 8.0\% (5 samples) 1:160; 3.2\% (2 samples) 1:320 and 1.6\% (1 sample) 1:640. From this result 20 of the sorologicamente positive dogs for accomplishment of the inhaled one of borne marrow had been selected. Of these, $85 \%$ (17) had presented forms amastigotas of Leishmania sp. This is the first register of the detention of sorologicamente positive dogs for Leishmania at Municipality of São Vicente Férrer, in state of Pernambuco, Brazil.
\end{abstract}

Keywords: visceral canine leishmaniasis; zoonoses; immunodiagnostic

A leishmaniose visceral canina (LVC) é uma doença sistêmica grave, de curso lento e crônico, difícil diagnóstico e cura parasitológica improvável (Melo, 2004; Ribeiro, 2005), acomete canídeos domésticos e silvestres, tendo como agente causal no Brasil a Leishmania (Leishmania) chagasi (Miles et al., 1999; Mauricio et al., 2000).

O cão tem sido implicado como principal hospedeiro e importante reservatório na cadeia epidemiológica da infecção em ambiente doméstico, cuja transmissão é dependente da população de Lutzomyia longipalpis (Paranhos-Silva et al., 1996; Almeida et al., 2005). Porém, em áreas silvestres e sinantrópicas, outros vertebrados como roedores, marsupiais, primatas e canídeos silvestres podem estar envolvidos no ciclo de transmissão da doença (Deane e Deane, 1955; Deane, 1956).
A principal fonte de infecção para o homem são canídeos. A enzootia canina tem precedido a ocorrência de casos humanos, sendo mais prevalente do que no homem (Castro, 1996). Com a identificação e eliminação dos cães infectados, podem-se desenvolver ações de controle contra a leishmaniose, pois se espera que, diminuindo-se a prevalência da doença canina, haja redução da incidência humana. Entretanto, é referido que no Brasil mais de 30\% dos cães infectados são assintomáticos (Acha e Szyfres, 1991).

Para o diagnóstico da leishmaniose, o encontro do parasita constitui requisito básico, mas os métodos sorológicos como o teste de imunofluorescência indireta (IFI) e o teste de aglutinação direta (DAT) são úteis para uma triagem de casos ou em inquéritos epidemiológicos.

* Departamento de Parasitologia, Centro de Pesquisas Aggeu Magalhães/CPqAM/Fundação Oswaldo Cruz/Fiocruz - Campus da UFPE - Av. Moraes Rego s/n, Pernambuco, Brasil. E-mail: otasilva@cpqam.fiocruz.br

** Departamento de Biologia e Medicina Veterinária, Universidade Estadual do Maranhão - UEMA, Rua Godofredo Viana, n. 1300, Centro, Imperatriz, Maranhão, Brasil. E-mail: geovaniab@yahoo.com.br 
Em estudo no município de São Vicente Férrer observaramse características interessantes da doença. Por informação da Fundação Nacional de Saúde (Funasa), durante as coletas por capturas de flebotomíneos não se tem encontrado o vetor L. longipalpis, considerado o principal transmissor da doença. Observou-se ainda a ausência de casos humanos durante todo o período da pesquisa, embora existisse uma considerável incidência de cães domésticos sorologicamente positivos.

Com base nesses fatos, principiou-se um estudo sobre a ocorrência de LVC na população canina do município de São Vicente Férrer, estado de Pernambuco, por meio de inquérito soroepidemiológico. No período de julho de 2003 a julho de 2005, foram coletadas amostras de sangue de 503 cães domésticos, através de punção asséptica da veia cefálica, aproximadamente $10 \mathrm{ml}$, para exame sorológico pelo teste de IFI, onde as amostras foram colhidas aleatoriamente de cães de diversas raças, sexo e idade variadas nos domicílios localizados em sítios do município.

Após a centrifugação, os soros foram transferidos para microtubos plásticos próprios, identificados e congelados a $20^{\circ} \mathrm{C}$, até realização do exame sorológico. Para cada animal preencheu-se ficha de identificação padronizada com dados referentes ao estado geral, raça, sexo, idade, porte, a sua procedência, condição clínica do mesmo e se existia presença de uma ou mais alterações compatíveis com a sintomatologia

\section{Referências}

ACHA, P.N.; SZYFRES, B. Visceral leishmaniasis. In: Zoonoses and communicable diseases common to man and animals. Washington: OPAS Pan American Health Organization, 1991. p. 648.

ALMEIDA, M. A. O.; JESÚS E. E. V.; SOUSA-ATTAM. L. B.; ALVES L. C.; BERNE M. E. A.; ATTA A. M. Clinical and serological aspects of visceral leishmaniasis in Northeast Brazilian dogs naturally infected with Leishmania chagasi. Vet.Parasitol, v. 127, p. 227-232, 2005.

CASTRO, A. G. Controle, diagnóstico e tratamento da leishmaniose visceral(calazar). 2. ed. Brasília: Fundação Nacional de Saúde, 1996. $88 \mathrm{p}$.

DEANE, L.M.; DEANE, M.P. Leishmaniose visceral urbana (no cão e no homem) em Sobral, Ceará. Hospital, v. 47, p. 75-87, 1055.

DEANE, L.M. Leishmaniose visceral no Brasil, Rio de Janeiro. Serviço Nacional de Educação Sanitária, 1956. da leishmaniose canina. Também, algumas informações acerca do proprietário do animal se fizeram necessárias, como ao mesmo tempo uma declaração de autorização para que estes proprietários consentissem o acesso ao seu animal e recolhimento do mesmo, caso fosse necessário.

Preliminarmente, foram processadas 503 amostras de soro, das quais 62 amostras (12,33\%) estavam positivas para Leishmania. Quanto às titulações encontradas nos soros reagentes 48 amostras $(77,42 \%)$ apresentaram títulos de $1: 40 ; 6(9,68 \%)$ de $1: 80 ; 5(8,06 \%)$ de $1: 160 ; 2$ (3,23\%) de $1: 320$ e $1(1,61 \%)$ de $1: 640$. A partir desses resultados foram selecionados 20 dos cães sorologicamente positivos para realização da biópsia de medula óssea, através da técnica de punção com aspiração medular. Destes, 17 animais (85\%) tiveram formas amastigotas de Leishmania.

As localidades com animais positivos estão focalizados próximos de pequenas áreas de mata característica da região, o que viabilizaria a presença do vetor junto às residências (Acha, 1991). Em consideração aos resultados obtidos, tornou-se necessário um estudo de maior amplitude, com maiores informações epidemiológicas e vigilância entomológica, o isolamento do agente etiológico e a captura com identificação do vetor e dos animais portadores que fazem parte da cadeia epidemiológica, agindo como elo de manutenção desta enfermidade.

MAURÍCIO, I. L.; STOTHARD, J. R.; MILES, M. A. The strange case of Leishmania chagasi. Parasitol. Today, v. 16, p. 188-189, 2000.

MELO, M. N. Leishmaniose Visceral no Brasil: desafios e perspectivas. Rev. H. Bras. Parasitol. Vet., v. 13, supl. 1, p. 41-45, 2004.

MILES, M.A.; VEXENAT, J.A.; FURTADO CAMPOS, J.H.;FONSECADE CASTRO, J.A. Canine leishmaniasis in Latin América: control strategies for visceral leishmaniasis. In: Canine Leishmaniasis: an update. Hoechst Roussel Vet. Pp. 46-53, 1999.

PARANHOS-SILVA, M.; FREITAS, L. A. R.; SANTOS, W.C.; GRIMALDI JR, G.; PONTES-DE-CARVALHO, L.C.; OLIVEIRA-DOS-SANTOS, A.J. A cross-sectional serodiagnostic survey of canine leishmaniasis due to Leishmania chagasi. Am. J. Trop. Med. Hyg., Baltimore, v. 55, n. 1, p. 39-44, 1996.

RIBEIRO, V. M. Leishmaniose Visceral Canina: Nossos cães devem morrer? Cães de fato, Belo Horizonte, v. 41-42, p. 41-43, 2005. 